\title{
Measuring the Density of Different Materials by Using the Fast Neutron Beam and Associated Alpha Particle Technique
}

\author{
D. Sudac, K. Nad, Z. Orlic, J. Obhodas, and V. Valkovic
}

\begin{abstract}
It was demonstrated in the previous work that various threat materials could be detected inside the sea going cargo container by measuring the three variables, carbon and oxygen concentration and density of investigated material. Density was determined by measuring transmitted neutrons, which is not always practical in terms of setting up the instrument geometry. In order to enable more geometry flexibility, we have investigated the possibility of using the scattered neutrons in cargo material identification. For that purpose, the densities of different materials were measured depending on the position of neutron detectors and neutron generator with respect to the target position. One neutron detector was put above the target, one behind and one in front of the target, above the neutron generator. It was shown that all three positions of neutron detectors can be successfully used to measure the target density, but only if the detected neutrons are successfully discriminated from the gamma rays.
\end{abstract}

Index Terms-.

$\mathbf{I}$ T IS well known that common explosives and illicit drugs are made from the light elements $\mathrm{H}, \mathrm{C}, \mathrm{N}$ and $\mathrm{O}$, which quantities can be measured by using the neutron interrogation techniques [1]-[3], and the compositions of these substances are well separated from the most common materials in one or more elemental features. Explosives are distinguished by relative high proportions of nitrogen and oxygen, while illicit drugs are generally rich in hydrogen and carbon [4]. Many explosives have densities which are generally larger than most everyday HCNO substances. Although some explosives can be detected by measuring the high nitrogen content (like Research Department Formula X, RDX), it is shown in the Fig. 1 that Semtex 1A can easily be misinterpreted as a paper [5]. However, by measuring densities of Semtex $1 \mathrm{~A}$ and paper it is possible to prevent misinterpretation in a case when scintillation gamma ray detectors are used. Some types of explosives like Triacetone triperoxide TATP do not contain nitrogen at all. In addition,

Manuscript received May 06, 2015; revised October 07, 2015 and December 10, 2015; accepted January 24, 2016.

D. Sudac, K. Nad, Z. Orlic, and J. Obhodas are with the Rudjer Boskovic Institute, Bijenicka c. 54, 10000 Zagreb, Croatia (e-mail: dsudac@irb.hr, jobhodas@irb.hr, nad@irb.hr, zorlic@irb.hr).

V. Valkovic was with Rudjer Boskovic Institute, Bijenicka c. 54, 10000 Zagreb, Croatia. He is now at Kvintička 62, Zagreb, Croatia (e-mail: valkovic@irb.hr).

Color versions of one or more of the figures in this paper are available online at http://ieeexplore.iee.org.

Digital Object Identifier 10.1109/TNS.2016.2521901 custom officers are not only interested to detect the explosives and illicit drugs, but more often, they want to check whether or not the cargo manifest is in accordance with the measurements provided by the inspection system. To do the appropriate checking, the inspection system must provide as many parameters as possible, including the density measurements since the average density value can be extracted from the cargo manifest. It was shown on the Fig. 2 [6]-[7], that various materials inside the sea going cargo container can be identified by measuring the carbon and oxygen content together with the density of investigated materials. For this purpose, the gamma ray detectors in the transmission position were used, while the gamma ray detectors on the top of the container were not so successful, because the scattered neutrons were not adequately separated from the gamma rays. It should be noted that the measurement time, which was long in the above case, actually depended on the number of the available gamma ray detectors. For instance, in the case of the EURITRACK system, the measurement time was no more than 10 minutes [8], [11].

In the research presented the densities of different materials (empty box, textile, iron wires, cigarettes, hexogen (RDX) simulant, flour, paper, TNT simulant, sugar, rice, sugar (dense), soil, sand, graphite) were measured by associated alpha particle technique (associate particle imaging, API) with neutron detectors at three different positions with respect to the target and API-120 neutron generator (NG), produced by ThermoElectron.

The associated $\alpha$ particle method [9]-[11] was proposed and used many years ago in neutron-charged particle coincidence measurements from $14 \mathrm{MeV}$ neutron induced reactions [12] and [13].

The API technique is based on the electronic "collimation" of the neutron beam generated by the ${ }^{3} \mathrm{H}(\mathrm{d}, \mathrm{n}){ }^{4} \mathrm{He}$ reaction, by detecting alpha particles emitted in a known solid angle in coincidence with neutrons.

\section{EXPERIMENTAL SETUP}

NE-218 $3^{\prime \prime} \times 3^{\prime \prime}$ neutron detector was put behind the target to measure transmitted neutrons $84 \mathrm{~cm}$ distant from the target. Scattered neutrons were measured with NE-218 and NE-213 $3^{\prime \prime} \times 3^{\prime \prime}$ neutron detectors at positions above the target and in the front of the target above the neutron generator at $86 \mathrm{~cm}$ and $93 \mathrm{~cm}$ from the target, respectively. 


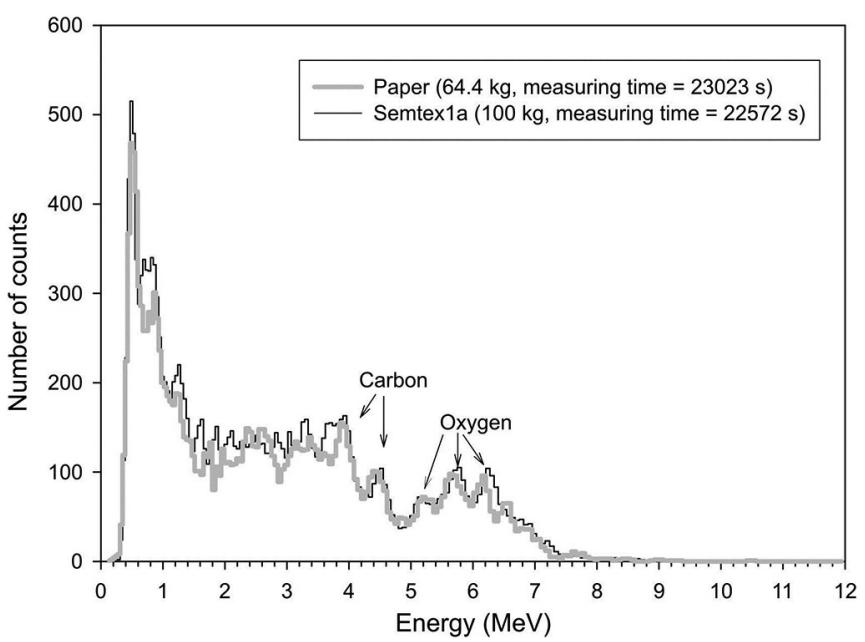

F1:1 Fig. 1. Gamma ray spectra of the explosive semtex1a (gray) and the paper $\mathrm{F} 1: 2$ (black) measured with two $3^{\prime \prime} \times 3^{\prime \prime} \mathrm{NaI}(\mathrm{Tl})$ gamma ray detectors. Although F1:3 some explosives can be detected by measuring the high nitrogen content (like F1:4 RDX), Semtex1A easily can be misinterpreted as a paper [5].

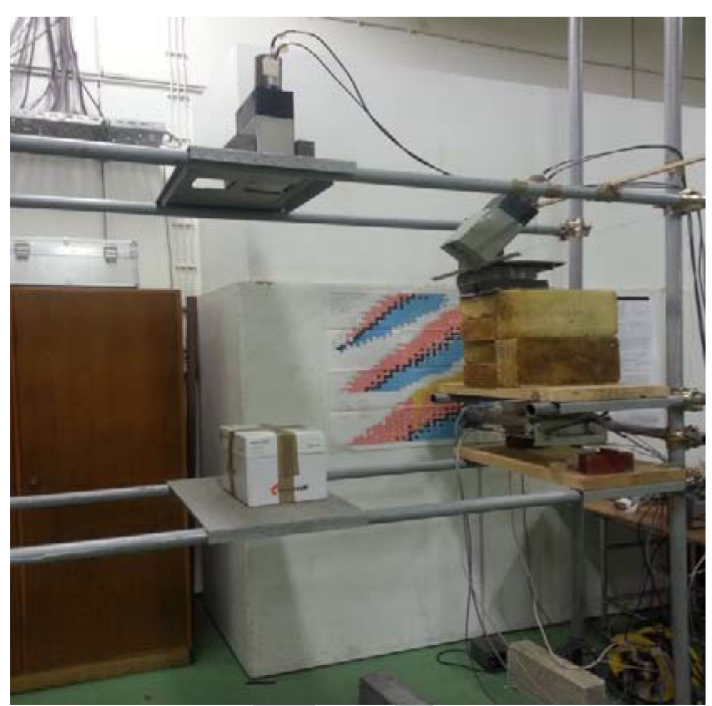

Fig. 3. Experimental set-up showing the position of the top and reflection F3:1 detectors.

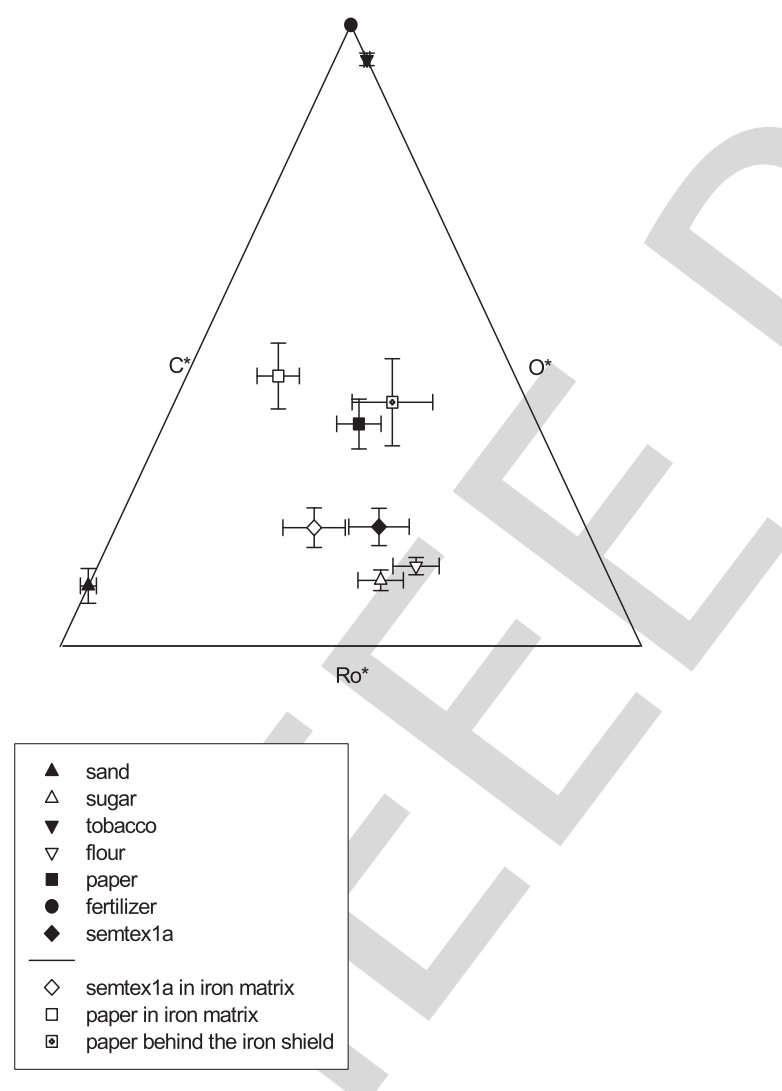

F2:1 Fig. 2. Semtex1a and semtex1a in iron matrix are well separated in triangle F2:2 diagram from the other materials including paper which has similar carbon to F2:3 oxygen ratio. Ro* $\mathrm{C}^{*}$ and $\mathrm{O}^{*}$ depend on target density, carbon content and F2:4 oxygen content. Transmission detectors were used [6]-[7]. The data points have F2:5 one sigma error bar.
The NE-213 detector was shielded from neutron generator with layers of wood, paraffin and lead. Target was a box of the volume $22 \times 23 \times 31 \mathrm{~cm}^{3}, 85 \mathrm{~cm}$ distant from the neutron generator. NG is equipped with the YAP:Ce scintillator which serve as an alpha detector. Diameter of the tagged neutron cone at the target position was equal to $24 \mathrm{~cm}$. For each target and for each neutron detector a time-of-flight of neutrons and gamma rays were measured. In this way it is possible to separate the neutrons scattered to the neutron detectors from the gamma rays produced by inelastic A(n,n' $\gamma)$ A scattering. Fig. 3 shows the picture while Fig. 4 shows the sketch of the experimental setup. Table I show different targets used in the experiment. Targets were chosen to represent the most common goods found in the sea going cargo container together with the different types of explosive simulants. The chosen materials were packed in the boxes following the usual practice of the sea going cargo containers packaging. This was the reason why we had analyzed two types of sugar targets. One contained pieces of $1 \mathrm{~kg}$ sugar packing, and another one was completely filled with unpacked sugar.

It should be noted that according to [14], the general organic 102 cargo was present in more than half (62\%) of the sea going 103 cargo containers, while metallic cargo was accounting for 15\%. 104 The average cargo density is expected to be below $0.2 \mathrm{~g} / \mathrm{cm}^{3}$. $\quad 105$ 


\section{TABLE I}

TARGETS OF DIFFERENT DENSITIES USED IN THE EXPERIMENT. ALL TARGETS HAD THE SAME VOLUME $\left(22 \times 23 \times 31 \mathrm{CM}^{3}\right)$ EXCEPT THE GRAPHITE WHICH VOLUME WAS $20 \times 20 \times 31 \mathrm{CM}^{3}$. IN SOME CASES TARGET BOXES WERE NOT COMPLETELY FILLED

\begin{tabular}{lcc} 
Target & Mass $(\mathrm{kg})$ & Density $\left(\mathrm{g} / \mathrm{cm}^{3}\right)$ \\
\hline Empty box & 0.2 & 0.01 \\
Textile & 1.1 & 0.07 \\
Iron freight & 2.9 & 0.185 \\
Cigarettes & 3.6 & 0.23 \\
RDX simulant & 10.4 & 0.66 \\
Flour & 12 & 0.765 \\
Paper & 12 & 0.765 \\
TNT simulant & 12.7 & 0.81 \\
Sugar & 14.4 & 0.92 \\
Rice & 16 & 1.02 \\
Sugar (dense) & 20 & 1.275 \\
Soil & 21.5 & 1.37 \\
Sand & 25.6 & 1.63 \\
Graphite & 21.6 & 1.7 \\
\hline
\end{tabular}

\section{RESULTS AND Discussion}

Figs. 5-8 shows the time-of-flight (t-o-f) spectra normalized to the same number of emitted tagged neutrons. T-o-f spectrum is actually the pulse height distribution of the time differences between the moment when alpha particle hit the alpha detector and the moment when neutron/gamma ray scattered or transmitted through the target hit the neutron detector. T-o-f spectrums of the transmitted and scattered neutrons at each detector were well separated from the gamma rays coming from the target and NG. Only these neutrons were taken to be the measure of the target density. Fig. 9 shows the exponential decay of the transmitted neutron beam in dependence on the target density. Experimental points marked in black in Fig. 9 were fitted by using the following equation:

$$
f(\rho)=a e^{-b \rho}
$$

Where $a$ and $b$ are fitting parameters:

$$
\begin{aligned}
& a=204865 \pm 3288 \\
& b=(1.62 \pm 0.05) \frac{\mathrm{cm}^{3}}{\mathrm{~g}}
\end{aligned}
$$

Equation (1) is expected to be valid for a collimated beam of neutrons where parameter " $b$ " is attenuation parameter depending on total neutron cross section [15]. The gray dots in Fig. 9, belonging to the soil, sand and graphite target, do not follow the exponential curve. Soil, sand and graphite are too dense and multiple neutron scattering are responsible for deviation from the exponential curve.

Number of scattered neutrons rises with the density, as was shown in Figs. 10 and 11, according to the formula:

$$
f(\rho)=y 0\left(1-e^{-c \rho}\right)
$$

The fitting parameters for the top detector were:

$$
\begin{aligned}
y 0 & =1330 \pm 165 \\
c & =(1.3 \pm 0.3) \frac{\mathrm{cm}^{3}}{\mathrm{~g}},
\end{aligned}
$$

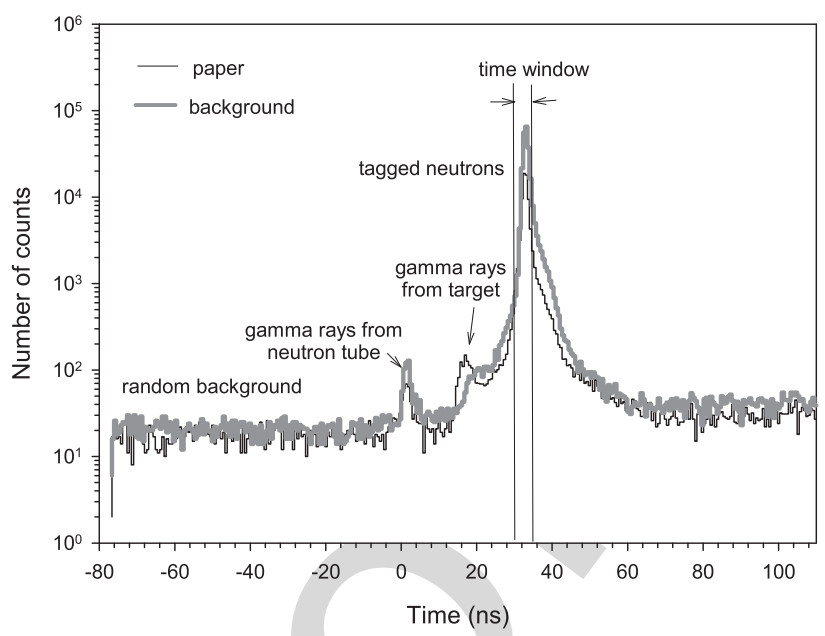

Fig. 5. The time-of-flight spectra for the transmission detector. Number of F5:1 counts in the indicated time window was used as a measure of the target density. F5:2

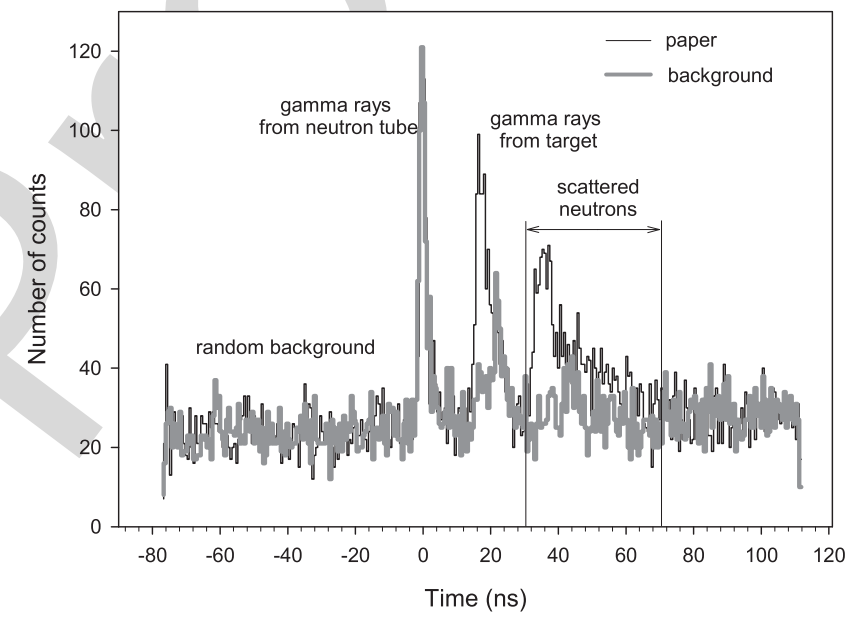

Fig. 6. The time-of-flight spectra for the top detector. Number of counts in F6:1 the indicated time window belonging to the scattered neutrons was used as a F6:2 measure of the target density.

F6:3

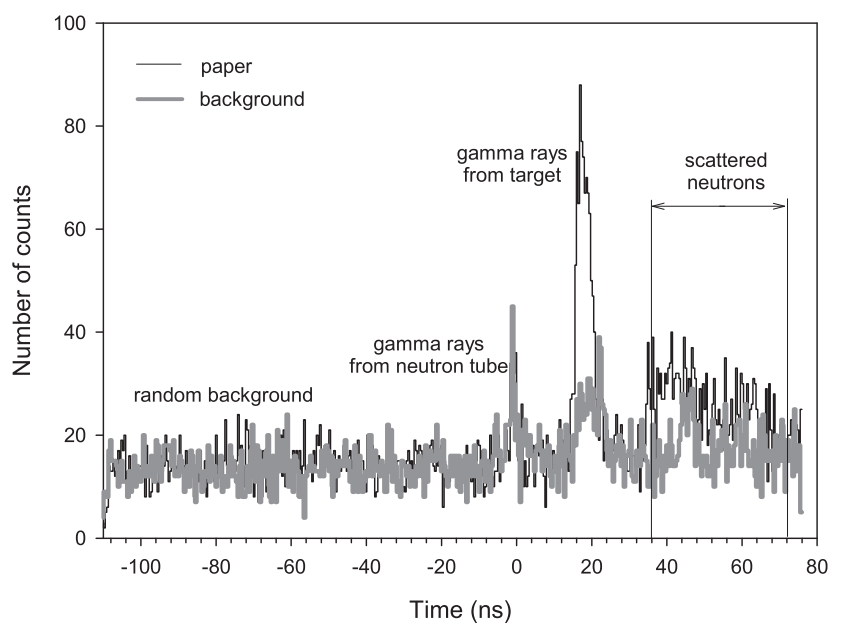

Fig. 7. The time-of-flight spectra for the reflection detector. Number of counts F7:1 in the indicated time window belonging to the scattered neutrons was used as a F7:2 measure of the target density. 


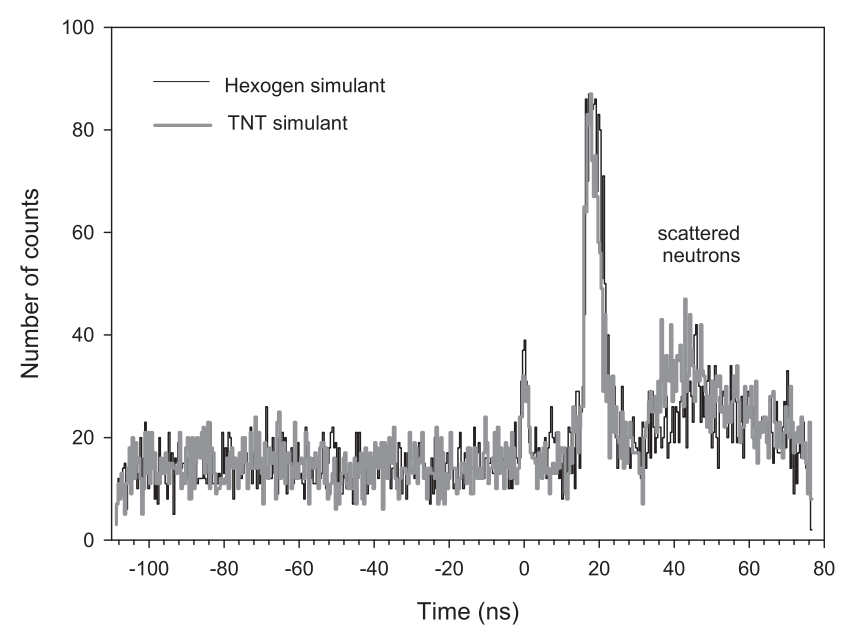

F8:1 Fig. 8. The time-of-flight spectra for the reflection detector for two different F8:2 targets, graphite and TNT simulant.

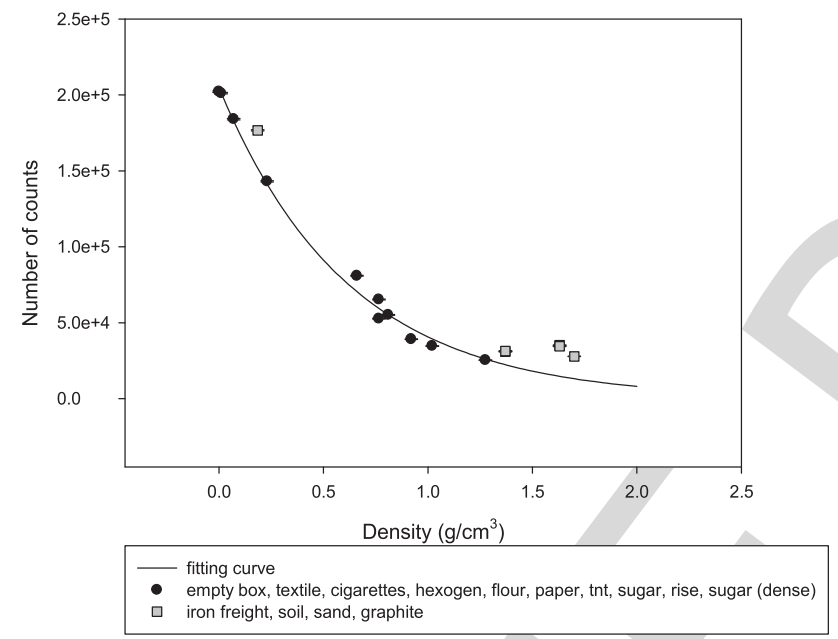

F9:1
Fig. 9. Number of counts in the indicated time window as a function of the target density (transmission detector). The data points have one sigma error bar.

and for the reflection detector:

$$
\begin{aligned}
y 0 & =1288 \pm 242 \\
c & =(0.9 \pm 0.3) \frac{\mathrm{cm}^{3}}{g} .
\end{aligned}
$$

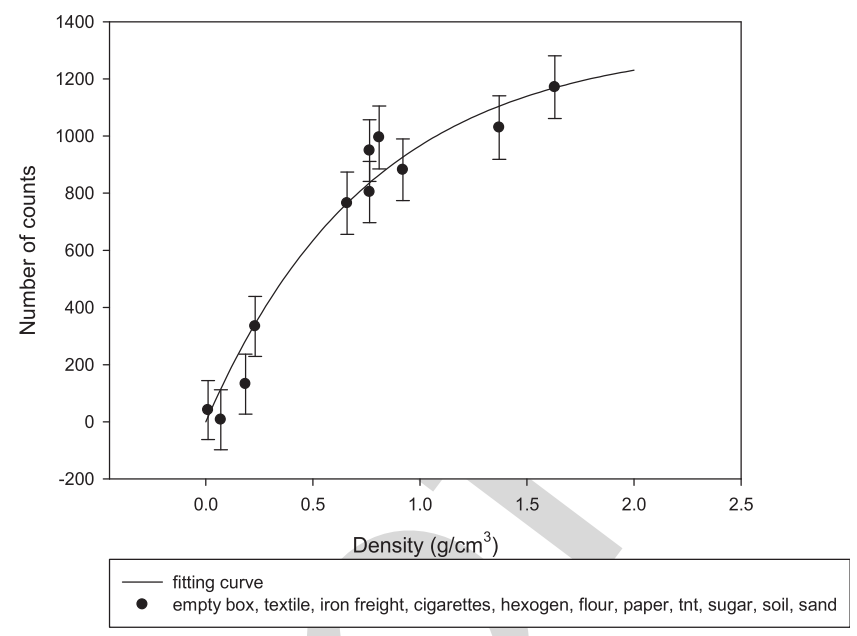

Fig. 10. Number of counts in the indicated time window as a function of the F10:1 target density (top detector). The data points have one sigma error bar.

F10:2

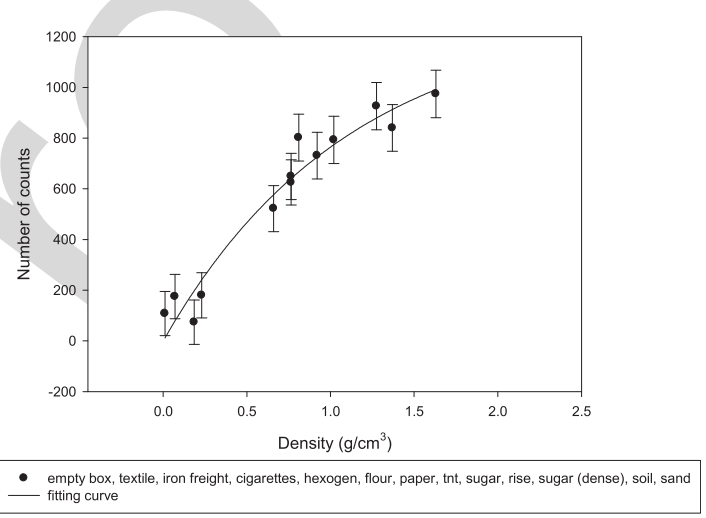

Fig. 11. Number of counts in the indicated time window as a function of the F11:1 target density (reflection detector). The data points have one sigma error bar.

F11:2

\section{CONCLUSION}

Target density can be measured with the neutron detector and 146 API technique regardless of the relative position of the detector 147 and the neutron generator. Generally this means that cargo con- 148 tainer can be inspected even if only one side of the container 149 is available for inspection. Number of transmitted neutrons 150 decreases exponentially while number of scattered neutrons 151 increases with density for materials of interest in this research 152 (C,H,N,O based materials). Transmitted neutrons show one 153 order of magnitude better sensitivity. Although API technique 154 was used to discriminate the neutrons from the gamma rays, it 155 is believed that the same results would be obtained by using the 156 pulse shape discrimination method. In that way API technique 157 can be avoided and the neutron generator which produces much 158 higher beam intensity than $10^{8} \mathrm{n} / \mathrm{s}$ can be used.

\section{REFERENCES}

[1] R. C. Runkle et al., "Photon and neutron interrogation techniques for 161 chemical explosives detection in air cargo: A critical review," Nucl. 162 Instrum. Methods Phys. Res. A, vol. 603, pp. 510-528, 2009.

[2] A. Buffler and J. Tickner, "Detecting contraband using neutrons: 164 Challenges and future directions," Radiat. Meas., vol. 45, pp. 1186-1192, 165 2010. 
[3] Z. D. Whetstone and K. J. Kearfott, "A review of conventional explosives detection using active neutron interrogation," J. Radioanal. Nucl. Chem., vol. 301, pp. 629-639, 2014.

[4] A. Buffler, "Contraband detection with fast neutrons," Radiat. Phys. Chem., vol. 71, pp. 853-861, 2004.

[5] D. Sudac, D. Matika, K. Na, and V. Valkovic, "Identification of materials hidden behind or in front of dense organic goods," Proc. IAEA Int. Topical Meeting Nuclear Research Applications and Utilization of Accelerators, Vienna, Austria: May 4, 8, 2009, Code 84190.

[6] D. Sudac et al., "Identification of materials hidden inside a container by using the $14 \mathrm{MeV}$ tagged neutron beam," Nucl. Instrum. Methods Phys. Res. B, vol. 261, pp. 321-325, 2007.

[7] D. Sudac, D. Matika, and V. Valkovic, "Identification of materials hidden inside a sea-going cargo container filled with an organic cargo by using the tagged neutron inspection system," Nucl. Instrum. Methods Phys. Res. $A$, vol. 589, pp. 47-56, 2008.

[8] C. Carasco et al., "In-field tests of the EURITRACK tagged neutron inspection system," Nucl. Instrum. Methods Phys. Res. A, vol. 588, pp. 397-405, 2008.

[9] D. L. Chichester, M. Lemchak, and J. D. Simpson, "The API 120: A portable neutron generator for the associated particle technique," Nucl. Instrum. Methods Phys. Res. B, vol. 241, pp. 753-758, 2005, and references therein.
[10] V. M. Bystritsky et al., Associated Particle Imaging Applied 190 to Inspection System for Bulky Cargo and Large Vehicles, 191 http://ntech.jinr.ru/?id=publications

[11] B. Perot et al., "Development of the EURITRACK tagged neutron inspec- 193 tion system," Nucl. Instrum. Methods Phys. Res. B, vol. 261, pp. 295-298, 194 2007, and references therein.

[12] đ. Miljanić, B. Antolković, and V. Valković, "Applications of time 196 measurements to charged particle detection in reaction with $14.4 \mathrm{MeV} 197$ neutrons," Nucl. Instrum. Methods, vol. 76, pp. 23-28, 1969.

[13] V. Valković et al., "Neutron-charged particle coincidence measurements 199 from 14.4 MeV neutron induced reactions," Nucl. Instrum. Methods, 200 vol. 76, pp. 29-34, 1969.

[14] J. Obhodas et al., "Analysis of containerized cargo in the ship container 202 terminal," Nucl. Instrum. Methods Phys. Res. A, vol. 619, pp. 460-466, 203 2010 .

[15] W. R. Leo, Techniques for Nuclear and Particle Physics Experiments, 205 Berlin, Germany: Springer-Verlag, 1987, p. 60.

[16] G. F. Knoll, Radiation Detection and Measurement, New York, NY, USA: 207 Wiley, 1979, p. 73. 


\section{QUERY}

Q1: Please supply index terms/keywords for your paper. To download the IEEE Taxonomy, go to http://www.ieee.org/documents/ taxonomy_v101.pdf. 


\title{
Measuring the Density of Different Materials by Using the Fast Neutron Beam and Associated Alpha Particle Technique
}

\author{
D. Sudac, K. Nad, Z. Orlic, J. Obhodas, and V. Valkovic
}

\begin{abstract}
It was demonstrated in the previous work that various threat materials could be detected inside the sea going cargo container by measuring the three variables, carbon and oxygen concentration and density of investigated material. Density was determined by measuring transmitted neutrons, which is not always practical in terms of setting up the instrument geometry. In order to enable more geometry flexibility, we have investigated the possibility of using the scattered neutrons in cargo material identification. For that purpose, the densities of different materials were measured depending on the position of neutron detectors and neutron generator with respect to the target position. One neutron detector was put above the target, one behind and one in front of the target, above the neutron generator. It was shown that all three positions of neutron detectors can be successfully used to measure the target density, but only if the detected neutrons are successfully discriminated from the gamma rays.
\end{abstract}

Index Terms-.

$\mathbf{I}$ $\mathrm{T}$ IS well known that common explosives and illicit drugs are made from the light elements $\mathrm{H}, \mathrm{C}, \mathrm{N}$ and $\mathrm{O}$, which quantities can be measured by using the neutron interrogation techniques [1]-[3], and the compositions of these substances are well separated from the most common materials in one or more elemental features. Explosives are distinguished by relative high proportions of nitrogen and oxygen, while illicit drugs are generally rich in hydrogen and carbon [4]. Many explosives have densities which are generally larger than most everyday HCNO substances. Although some explosives can be detected by measuring the high nitrogen content (like Research Department Formula X, RDX), it is shown in the Fig. 1 that Semtex 1A can easily be misinterpreted as a paper [5]. However, by measuring densities of Semtex $1 \mathrm{~A}$ and paper it is possible to prevent misinterpretation in a case when scintillation gamma ray detectors are used. Some types of explosives like Triacetone triperoxide TATP do not contain nitrogen at all. In addition,

Manuscript received May 06, 2015; revised October 07, 2015 and December 10, 2015; accepted January 24, 2016.

D. Sudac, K. Nad, Z. Orlic, and J. Obhodas are with the Rudjer Boskovic Institute, Bijenicka c. 54, 10000 Zagreb, Croatia (e-mail: dsudac@irb.hr, jobhodas@irb.hr, nad@irb.hr, zorlic@irb.hr).

V. Valkovic was with Rudjer Boskovic Institute, Bijenicka c. 54, 10000 Zagreb, Croatia. He is now at Kvintička 62, Zagreb, Croatia (e-mail: valkovic@irb.hr).

Color versions of one or more of the figures in this paper are available online at http://ieeexplore.iee.org.

Digital Object Identifier 10.1109/TNS.2016.2521901 custom officers are not only interested to detect the explosives and illicit drugs, but more often, they want to check whether or not the cargo manifest is in accordance with the measurements provided by the inspection system. To do the appropriate checking, the inspection system must provide as many parameters as possible, including the density measurements since the average density value can be extracted from the cargo manifest. It was shown on the Fig. 2 [6]-[7], that various materials inside the sea going cargo container can be identified by measuring the carbon and oxygen content together with the density of investigated materials. For this purpose, the gamma ray detectors in the transmission position were used, while the gamma ray detectors on the top of the container were not so successful, because the scattered neutrons were not adequately separated from the gamma rays. It should be noted that the measurement time, which was long in the above case, actually depended on the number of the available gamma ray detectors. For instance, in the case of the EURITRACK system, the measurement time was no more than 10 minutes [8], [11].

In the research presented the densities of different materials (empty box, textile, iron wires, cigarettes, hexogen (RDX) simulant, flour, paper, TNT simulant, sugar, rice, sugar (dense), soil, sand, graphite) were measured by associated alpha particle technique (associate particle imaging, API) with neutron detectors at three different positions with respect to the target and API-120 neutron generator (NG), produced by ThermoElectron.

The associated $\alpha$ particle method [9]-[11] was proposed and used many years ago in neutron-charged particle coincidence measurements from $14 \mathrm{MeV}$ neutron induced reactions [12] and [13].

The API technique is based on the electronic "collimation" of the neutron beam generated by the ${ }^{3} \mathrm{H}(\mathrm{d}, \mathrm{n}){ }^{4} \mathrm{He}$ reaction, by detecting alpha particles emitted in a known solid angle in coincidence with neutrons.

\section{EXPERIMENTAL SETUP}

NE-218 $3^{\prime \prime} \times 3^{\prime \prime}$ neutron detector was put behind the target to measure transmitted neutrons $84 \mathrm{~cm}$ distant from the target. Scattered neutrons were measured with NE-218 and NE-213 $3^{\prime \prime} \times 3^{\prime \prime}$ neutron detectors at positions above the target and in the front of the target above the neutron generator at $86 \mathrm{~cm}$ and $93 \mathrm{~cm}$ from the target, respectively. 


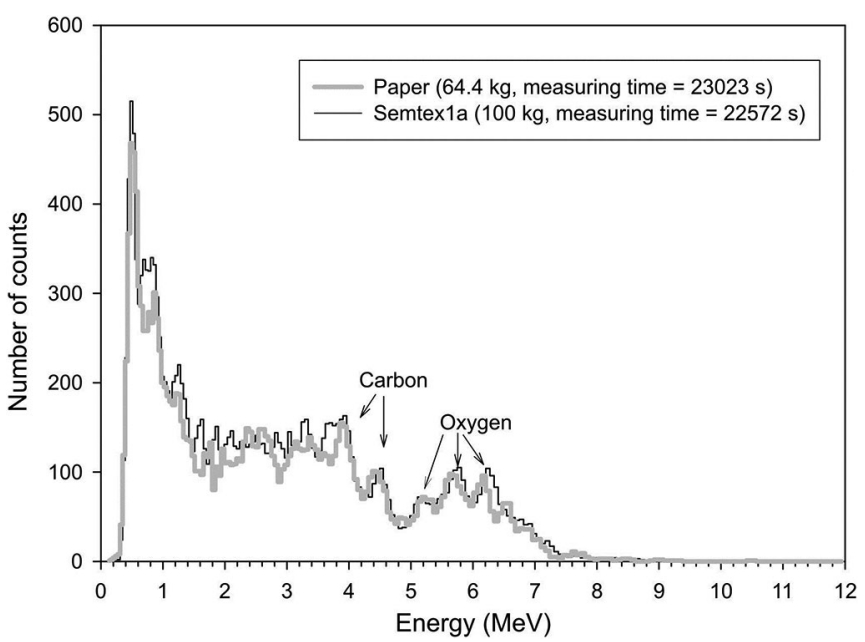

F1:1 Fig. 1. Gamma ray spectra of the explosive semtex1a (gray) and the paper $\mathrm{F} 1: 2$ (black) measured with two $3^{\prime \prime} \times 3^{\prime \prime} \mathrm{NaI}(\mathrm{Tl})$ gamma ray detectors. Although F1:3 some explosives can be detected by measuring the high nitrogen content (like F1:4 RDX), Semtex1A easily can be misinterpreted as a paper [5].

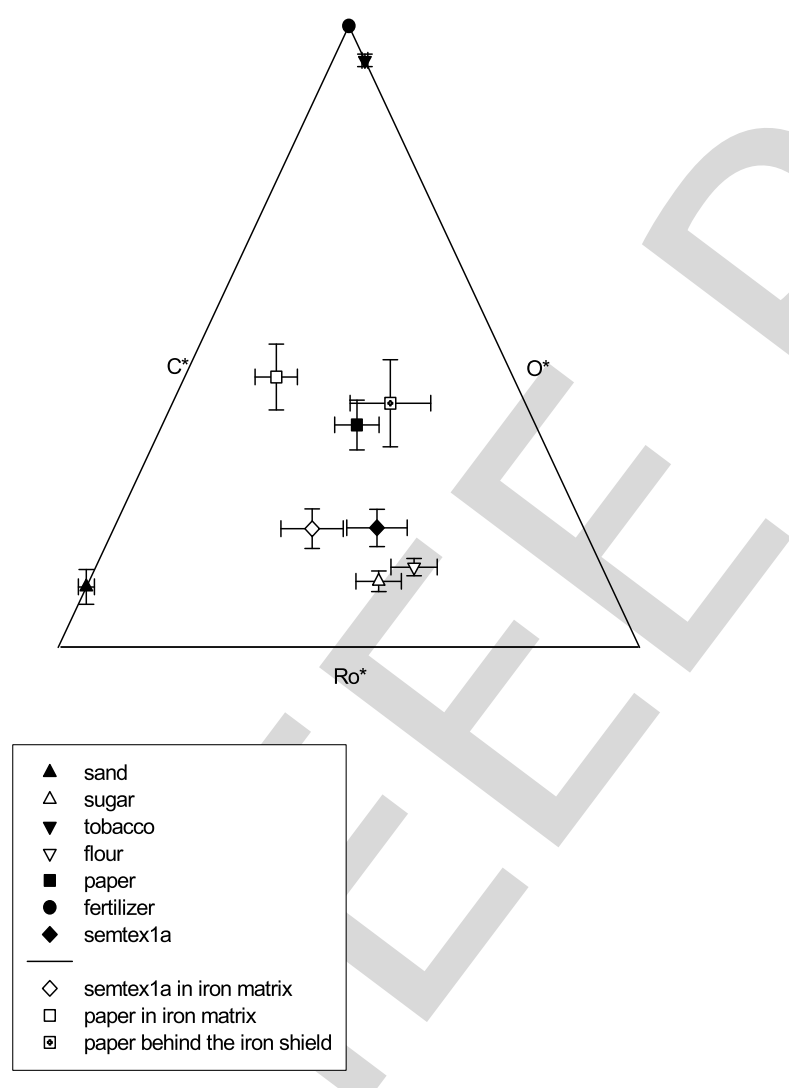

F2:1 Fig. 2. Semtex1a and semtex1a in iron matrix are well separated in triangle F2:2 diagram from the other materials including paper which has similar carbon to $\mathrm{F} 2: 3$ oxygen ratio. $\mathrm{Ro}^{*}, \mathrm{C}^{*}$ and $\mathrm{O}^{*}$ depend on target density, carbon content and F2:4 oxygen content. Transmission detectors were used [6]-[7]. The data points have
The NE-213 detector was shielded from neutron generator with layers of wood, paraffin and lead. Target was a box of the volume $22 \times 23 \times 31 \mathrm{~cm}^{3}, 85 \mathrm{~cm}$ distant from the neutron generator. NG is equipped with the YAP:Ce scintillator which serve as an alpha detector. Diameter of the tagged neutron cone at the

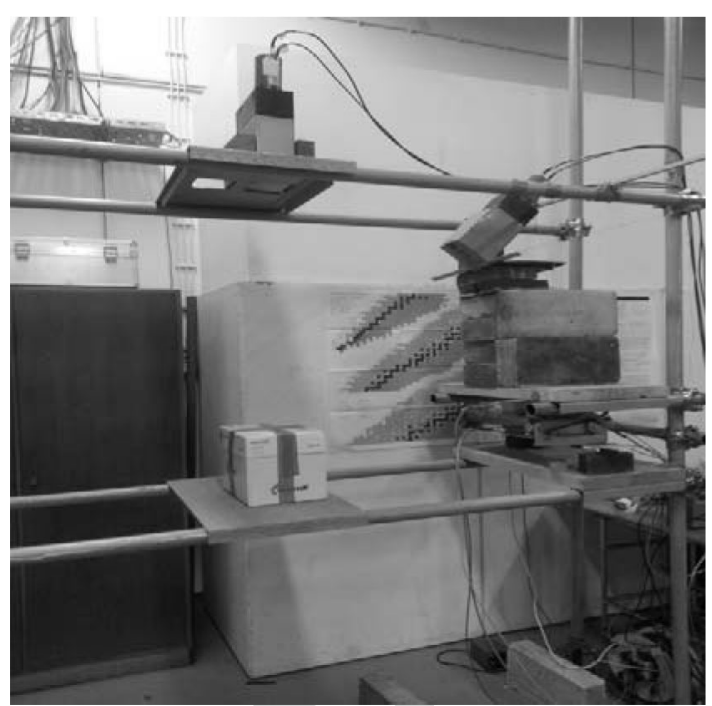

Fig. 3. Experimental set-up showing the position of the top and reflection F3:1 detectors.

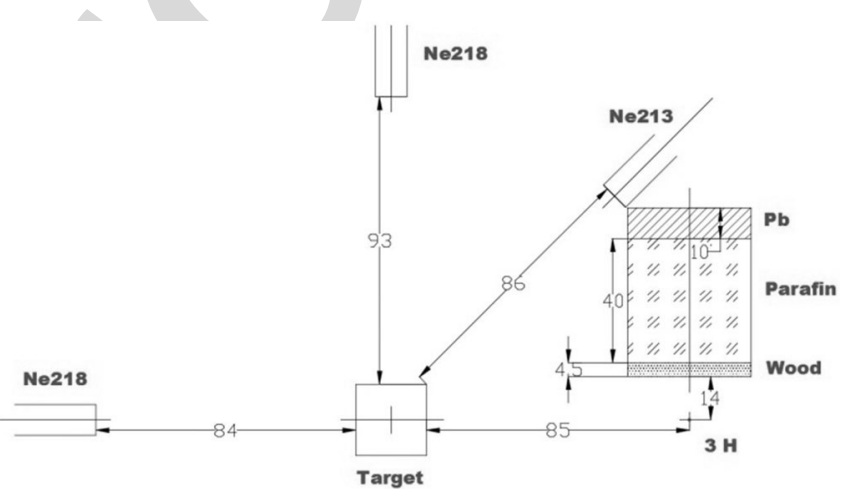

Fig. 4. Experimental set-up. Position of the neutron generator (NG) is marked F4:1 with $3 \mathrm{H}$. Dimensions are in centimeters. The top detector is above the target, F4:2 the reflection detector is above the NG and the third detector is in transmission F4:3 position.

target position was equal to $24 \mathrm{~cm}$. For each target and for each neutron detector a time-of-flight of neutrons and gamma rays were measured. In this way it is possible to separate the neutrons scattered to the neutron detectors from the gamma rays produced by inelastic A(n,n' $\gamma)$ A scattering. Fig. 3 shows the picture while Fig. 4 shows the sketch of the experimental setup. Table I show different targets used in the experiment. Targets were chosen to represent the most common goods found in the sea going cargo container together with the different types of explosive simulants. The chosen materials were packed in the boxes following the usual practice of the sea going cargo containers packaging. This was the reason why we had analyzed two types of sugar targets. One contained pieces of $1 \mathrm{~kg}$ sugar packing, and another one was completely filled with unpacked sugar.

It should be noted that according to [14], the general organic 102 cargo was present in more than half (62\%) of the sea going 103 cargo containers, while metallic cargo was accounting for 15\%. 104 The average cargo density is expected to be below $0.2 \mathrm{~g} / \mathrm{cm}^{3}$. $\quad 105$ 
TABLE I

TARGETS OF DIFFERENT DENSITIES USED IN THE EXPERIMENT. ALL TARGETS HAD THE SAME VOLUME $\left(22 \times 23 \times 31 \mathrm{CM}^{3}\right)$ EXCEPT THE GRAPHITE WHICH VOLUME WAS $20 \times 20 \times 31 \mathrm{CM}^{3}$. IN SOME CASES TARGET BOXES WERE NOT COMPLETELY FILLED

\begin{tabular}{lcc} 
Target & Mass $(\mathrm{kg})$ & Density $\left(\mathrm{g} / \mathrm{cm}^{3}\right)$ \\
\hline Empty box & 0.2 & 0.01 \\
Textile & 1.1 & 0.07 \\
Iron freight & 2.9 & 0.185 \\
Cigarettes & 3.6 & 0.23 \\
RDX simulant & 10.4 & 0.66 \\
Flour & 12 & 0.765 \\
Paper & 12 & 0.765 \\
TNT simulant & 12.7 & 0.81 \\
Sugar & 14.4 & 0.92 \\
Rice & 16 & 1.02 \\
Sugar (dense) & 20 & 1.275 \\
Soil & 21.5 & 1.37 \\
Sand & 25.6 & 1.63 \\
Graphite & 21.6 & 1.7 \\
\hline
\end{tabular}

\section{RESULTS AND Discussion}

Figs. 5-8 shows the time-of-flight (t-o-f) spectra normalized to the same number of emitted tagged neutrons. T-o-f spectrum is actually the pulse height distribution of the time differences between the moment when alpha particle hit the alpha detector and the moment when neutron/gamma ray scattered or transmitted through the target hit the neutron detector. T-o-f spectrums of the transmitted and scattered neutrons at each detector were well separated from the gamma rays coming from the target and NG. Only these neutrons were taken to be the measure of the target density. Fig. 9 shows the exponential decay of the transmitted neutron beam in dependence on the target density. Experimental points marked in black in Fig. 9 were fitted by using the following equation:

$$
f(\rho)=a e^{-b \rho}
$$

Where $a$ and $b$ are fitting parameters:

$$
\begin{aligned}
& a=204865 \pm 3288 \\
& b=(1.62 \pm 0.05) \frac{\mathrm{cm}^{3}}{\mathrm{~g}}
\end{aligned}
$$

Equation (1) is expected to be valid for a collimated beam of neutrons where parameter " $b$ " is attenuation parameter depending on total neutron cross section [15]. The gray dots in Fig. 9, belonging to the soil, sand and graphite target, do not follow the exponential curve. Soil, sand and graphite are too dense and multiple neutron scattering are responsible for deviation from the exponential curve.

Number of scattered neutrons rises with the density, as was shown in Figs. 10 and 11, according to the formula:

$$
f(\rho)=y 0\left(1-e^{-c \rho}\right)
$$

The fitting parameters for the top detector were:

$$
\begin{aligned}
y 0 & =1330 \pm 165 \\
c & =(1.3 \pm 0.3) \frac{\mathrm{cm}^{3}}{\mathrm{~g}},
\end{aligned}
$$

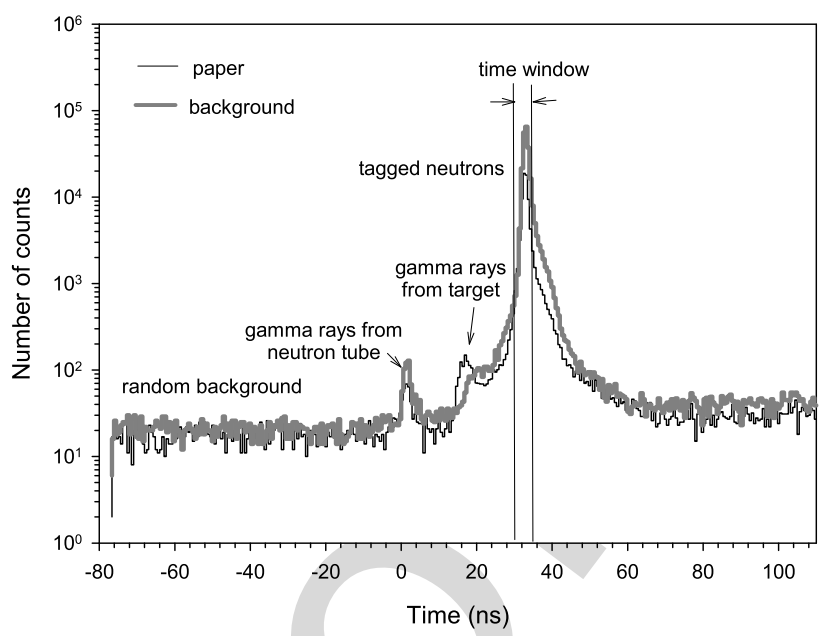

Fig. 5. The time-of-flight spectra for the transmission detector. Number of F5:1 counts in the indicated time window was used as a measure of the target density. F5:2

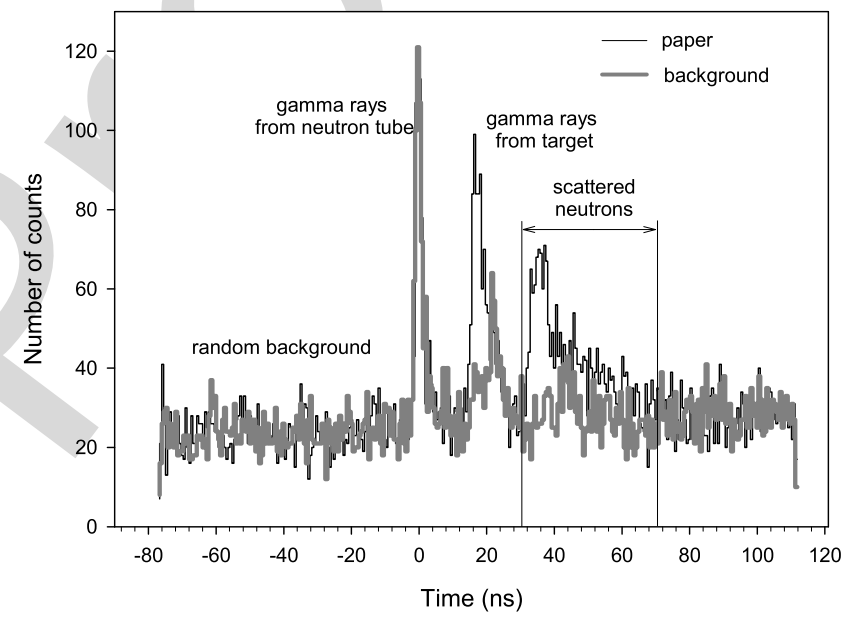

Fig. 6. The time-of-flight spectra for the top detector. Number of counts in F6:1 the indicated time window belonging to the scattered neutrons was used as a F6:2 measure of the target density.

F6:3

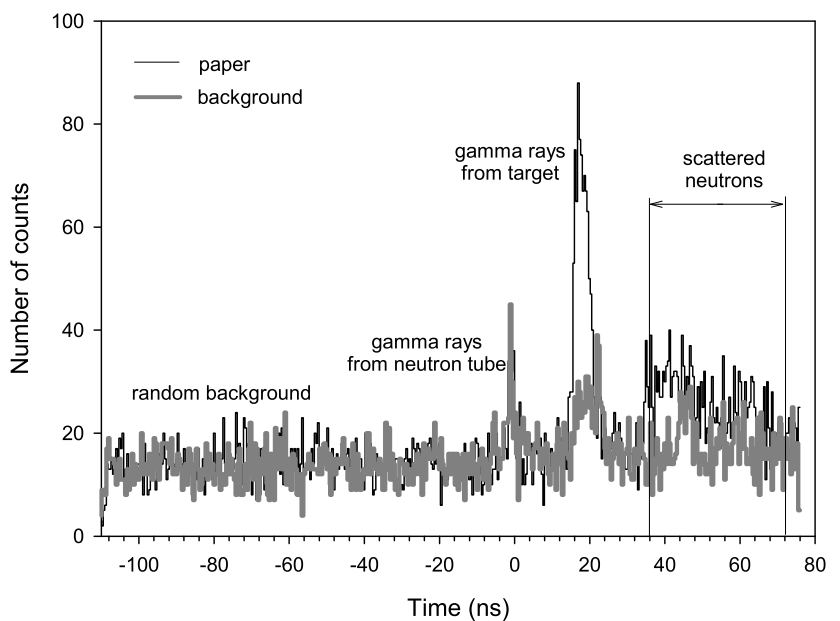

Fig. 7. The time-of-flight spectra for the reflection detector. Number of counts F7:1 in the indicated time window belonging to the scattered neutrons was used as a F7:2 measure of the target density. 


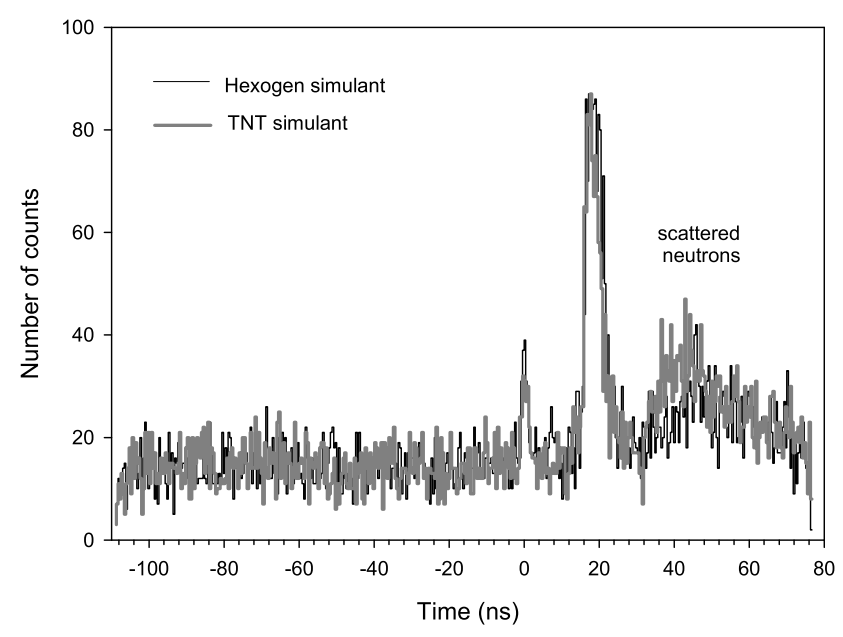

F8:1 Fig. 8. The time-of-flight spectra for the reflection detector for two different F8:2 targets, graphite and TNT simulant.

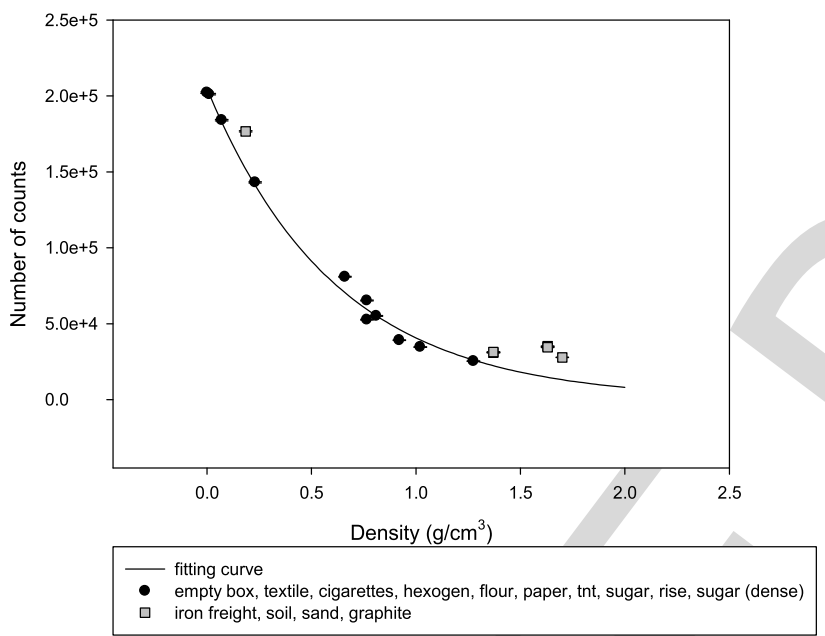

F9:1

F9:2

F9:3
Fig. 9. Number of counts in the indicated time window as a function of the target density (transmission detector). The data points have one sigma error bar.

and for the reflection detector:

$$
\begin{aligned}
y 0 & =1288 \pm 242 \\
c & =(0.9 \pm 0.3) \frac{\mathrm{cm}^{3}}{\mathrm{~g}} .
\end{aligned}
$$

If eq. (1) is valid, one would expect that eq. (3) is valid too, with the same attenuation parameter. The parameters " $\mathrm{b}$ " and two "c" parameters obtained by eq. (1) and eq. (3), respectively, are not quite the same, but if the error bars are taken in the account, they are not very different either. The matrix around the target can influence equations and parameters determined by (3-5). Matrix influence was studied in [5]-[7].

It has been shown that triangular graph can be made from results obtained by carbon, oxygen and density measurements and that the target material can be identified even if the target is surrounded with iron or organic matrix. The most difficult case is a target placed inside the organic matrix made from materials listed in Table I.

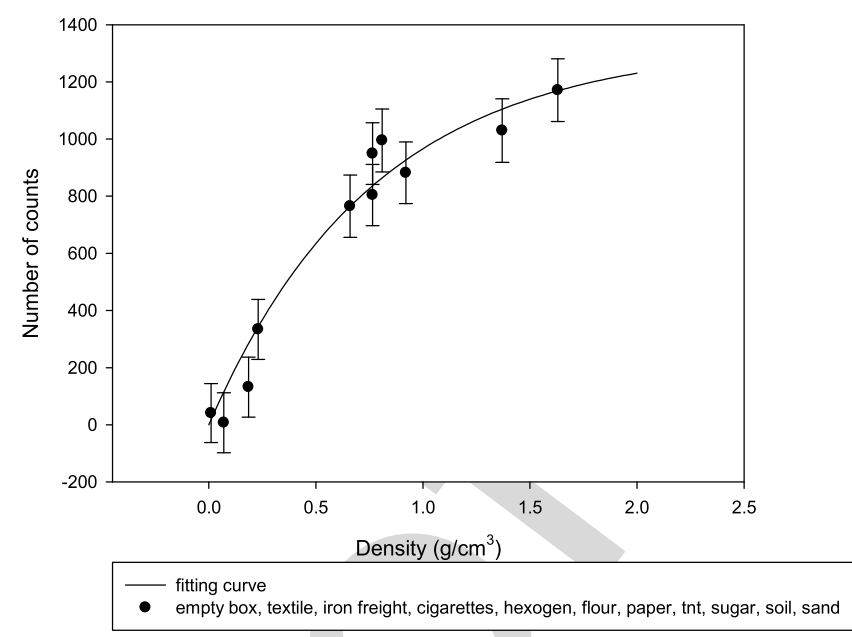

Fig. 10. Number of counts in the indicated time window as a function of the F10:1 target density (top detector). The data points have one sigma error bar.

F10:2

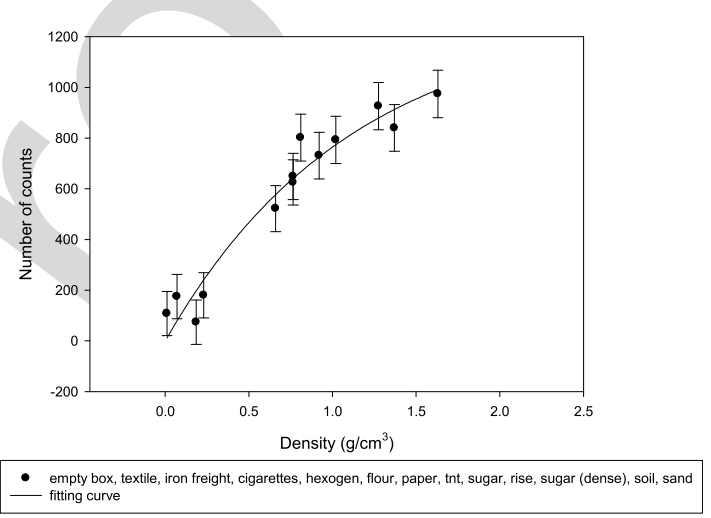

Fig. 11. Number of counts in the indicated time window as a function of the F11:1 target density (reflection detector). The data points have one sigma error bar.

F11:2

\section{CONCLUSION}

Target density can be measured with the neutron detector and 146 API technique regardless of the relative position of the detector 147 and the neutron generator. Generally this means that cargo con- 148 tainer can be inspected even if only one side of the container 149 is available for inspection. Number of transmitted neutrons 150 decreases exponentially while number of scattered neutrons 151 increases with density for materials of interest in this research 152 (C,H,N,O based materials). Transmitted neutrons show one 153 order of magnitude better sensitivity. Although API technique 154 was used to discriminate the neutrons from the gamma rays, it 155 is believed that the same results would be obtained by using the 156 pulse shape discrimination method. In that way API technique 157 can be avoided and the neutron generator which produces much 158 higher beam intensity than $10^{8} \mathrm{n} / \mathrm{s}$ can be used.

\section{REFERENCES}

[1] R. C. Runkle et al., "Photon and neutron interrogation techniques for 161 chemical explosives detection in air cargo: A critical review," Nucl. 162 Instrum. Methods Phys. Res. A, vol. 603, pp. 510-528, 2009.

[2] A. Buffler and J. Tickner, "Detecting contraband using neutrons: 164 Challenges and future directions," Radiat. Meas., vol. 45, pp. 1186-1192, 165 2010. 
[3] Z. D. Whetstone and K. J. Kearfott, "A review of conventional explosives detection using active neutron interrogation," J. Radioanal. Nucl. Chem., vol. 301, pp. 629-639, 2014.

[4] A. Buffler, "Contraband detection with fast neutrons," Radiat. Phys. Chem., vol. 71, pp. 853-861, 2004.

[5] D. Sudac, D. Matika, K. Na, and V. Valkovic, "Identification of materials hidden behind or in front of dense organic goods," Proc. IAEA Int. Topical Meeting Nuclear Research Applications and Utilization of Accelerators, Vienna, Austria: May 4, 8, 2009, Code 84190.

[6] D. Sudac et al., "Identification of materials hidden inside a container by using the $14 \mathrm{MeV}$ tagged neutron beam," Nucl. Instrum. Methods Phys. Res. B, vol. 261, pp. 321-325, 2007.

[7] D. Sudac, D. Matika, and V. Valkovic, "Identification of materials hidden inside a sea-going cargo container filled with an organic cargo by using the tagged neutron inspection system," Nucl. Instrum. Methods Phys. Res. A, vol. 589, pp. 47-56, 2008.

[8] C. Carasco et al., "In-field tests of the EURITRACK tagged neutron inspection system," Nucl. Instrum. Methods Phys. Res. A, vol. 588, pp. 397-405, 2008.

[9] D. L. Chichester, M. Lemchak, and J. D. Simpson, "The API 120: A portable neutron generator for the associated particle technique," Nucl. Instrum. Methods Phys. Res. B, vol. 241, pp. 753-758, 2005, and references therein.
[10] V. M. Bystritsky et al., Associated Particle Imaging Applied 190 to Inspection System for Bulky Cargo and Large Vehicles, 191 http://ntech.jinr.ru/?id=publications

[11] B. Perot et al., "Development of the EURITRACK tagged neutron inspec- 193 tion system," Nucl. Instrum. Methods Phys. Res. B, vol. 261, pp. 295-298, 194 2007, and references therein.

[12] đ. Miljanić, B. Antolković, and V. Valković, "Applications of time 196 measurements to charged particle detection in reaction with $14.4 \mathrm{MeV} 197$ neutrons," Nucl. Instrum. Methods, vol. 76, pp. 23-28, 1969.

[13] V. Valković et al., "Neutron-charged particle coincidence measurements 199 from 14.4 MeV neutron induced reactions," Nucl. Instrum. Methods, 200 vol. 76, pp. 29-34, 1969.

[14] J. Obhodas et al., "Analysis of containerized cargo in the ship container 202 terminal," Nucl. Instrum. Methods Phys. Res. A, vol. 619, pp. 460-466, 203 2010 .

[15] W. R. Leo, Techniques for Nuclear and Particle Physics Experiments, 205 Berlin, Germany: Springer-Verlag, 1987, p. 60.

[16] G. F. Knoll, Radiation Detection and Measurement, New York, NY, USA: 207 Wiley, 1979, p. 73. 


\section{QUERY}

Q1: Please supply index terms/keywords for your paper. To download the IEEE Taxonomy, go to http://www.iee.org/documents/ taxonomy_v101.pdf. 